\title{
KEBIJAKAN AKREDITASI RUMAH SAKIT UNTUK PELAYANAN KESELAMATAN PASIEN YANG BERMUTU
}

Ade sulistya lubis/181101121

\section{adesulistyalubis@gmail.com}

abstrak

Latar Belakang: Akreditasi rumah sakit adalah pengakuan terhadap rumah sakit yang diberikan oleh lembaga independen penyelenggara akreditasi yang ditetapkan oleh menteri kesehatan

Tujuan : untuk mengetahui kebijakan akreditasi rumah sakit untuk pelayan keselamatan pasien yang bermutu.Metode: tersearch dan analisis dari berbagai sumber seperti buku teks, buku referensi jurnal, e-book, dan juga membandingkan beberapa jurnal yang berhubungan dengan kebijakan akreditasi rumah sakit untuk pelayan keselamatan pasien yang bermutu.

Hasil: Akreditasi rumah sakit adalah pengakuan terhadap rumah sakit yang diberikan oleh lembaga independen penyelenggara akreditasi yang ditetapkan oleh menteri kesehatan, setelah dinilai bahwa rumah sakit itu memenuhi standar pelayanan rumah sakit yang berlaku untuk meningkatkan mutu pelayanan rumah sakit secara berkesinambungan

Kesimpulan: kebijakan akreditasi rumah sakit berpengaruh dalam peningkatan pelayanan keselamatan pasien yang bermutu.

\section{Kata kunci: kebijakan, akreditasi, keselamatan pasien}

Background: Hospital accreditation is recognition of hospitals provided by an independent accreditation body established by the minister of health

Objective: to find out hospital accreditation policies for quality patient safety services. Methods: search and analysis from various sources such as textbooks, journal reference books, e-books, and also compare several journals related to hospital accreditation policies for safety services. quality patient.

Results: Hospital accreditation is the recognition of hospitals provided by an independent accreditation provider established by the Ministry of Health, after assessing that the hospital meets the applicable hospital service standards to continuously improve the quality of hospital services

Conclusion: hospital accreditation policies have an effect on improving quality patient safety services.

Keywords: policy, accreditation, patient safety 


\section{LATAR BELAKANG PENDAHULUAN}

Akreditasi rumah sakit adalah pengakuan terhadap rumah sakit yang diberikan oleh lembaga independen penyelenggara akreditasi yang ditetapkan oleh menteri kesehatan, setelah dinilai bahwa rumah sakit itu memenuhi standar pelayanan rumah sakit yang berlaku untuk meningkatkan mutu pelayanan rumah sakit secara berkesinambungan (Permenkes No.12 tahun 2012 tentang Akreditasi Rumah Sakit).

Rumah sakit wajib melakukan akreditasi dalam upayanya meningkatkan mutu pelayanan secara berkala setiap 3 (tiga) tahun sekali. Hal ini tercantum dalam undang-undang nomor 44 tahun 2009 tentang Rumah Sakit, pasal 40 ayat 1, menyatakan bahwa, dalam upaya peningkatan mutu pelayanan rumah sakit wajib dilakukan akreditasi secara berkala menimal 3 (tiga) tahun sekali. Akreditasi wajib bagi semua rumah sakit baik rumah sakit publik/pemerintah maupun rumah sakit privat/swasta/BUMN.

Data dari KARS (Komisi Akreditasi Rumah Sakit) pada tahun 2015 tercatat baru 284 rumah sakit yang terakreditasi secara nasional dari 2.415 rumah sakit yang terdaftar di Indonesia. Jumlah rumah sakit yang belum terakreditasi yaitu 2.131 rumah sakit sehingga secara proporsi baru $11,75 \%$ rumah sakit yang terakreditasi di Indonesia. Oleh karena itu, komitmen dari pimpinan dan dukungan dari seluruh SDM yang ada di rumah sakit juga memiliki peran penting dalam mencapai keberhasilan. Pencapaian target akreditasi bukan hal yang mudah untuk dilakukan tanpa adanya komitmen dari pemilik rumah sakit untuk diakreditasi.

Keselamatan Pasien adalah suatu sistem yang membuat asuhan pasien lebih aman, meliputi asesmen risiko, identifikasi dan pengelolaan risiko pasien, pelaporan dan analisis insiden, kemampuan belajar dari insiden dan tindak lanjutnya, serta implementasi solusi untuk meminimalkan timbulnya risiko dan mencegah terjadinya cedera yang disebabkan oleh kesalahan akibat melaksanakan suatu tindakan atau tidak mengambil tindakan yang seharusnya diambil. 


\section{TUJUAN}

Tujuan pembandigan dari beberapa jurnal dan sumber lainnya agar dapat mengetahui kebijakan akreditasi rumah sakit untuk pelayanan keselamatan pasien yang bermutu.

\section{METODE}

Jurnal ini menggunakan metode tersearch dan analisis dari berbagai sumber seperti buku teks, buku referensi jurnal, e-book, dan juga membandingkan beberapa jurnal yang berhubungan dengan kebijakan akreditasi rumah sakit untuk pelayanan keselamatan pasien yang bermutu. Dari analisi berbagai sumber digunakan Untuk mengetahui bagaimana kebijakan perawat terhadap akreditasi rumah sakit untuk pelayanan keselamatan pasien yang bermutu. Penulisan jurnal ini dimulai pada tanggal 01 oktober 2019. Pengolahan jurnal dilakukan dengan metode membandingkan beberapa jurnal yang berhubungan kebijakan akreditasi rumah sakit untuk pelayanan keselamatan pasien yang bermutu.

\section{HASIL}

Dari jurnal (Fajrianti, Kania Nabila,Ahmad Muhtadi.2010. Peningkatan Mutu Pelayanan Kesehatan Di Rumah Sakit Dengan Six Sigma: Farmaka Volume 15 Nomor 3) Kualitas pelayanan dapat diartikan sebagai perbedaan antara pelayanan yang diterima secara nyata dengan harapan pelanggan. Di industri perawatan kesehatan, terdapat jenis-jenis pelayanan yang sama yang disediakan oleh rumah sakit, namun kualitas pelayanannya belum tentu sama. Pasien adalah pelanggan sehingga menjadi bagian yang sangat penting dalam perkembangan industri kesehatan (Setyaningsih, 2013).

Penyebab mutu pelayanan yang rendah di antaranya faktor input (peralatan, dana, kurangnya fasilitas, tenaga dokter ahli, dan sebagainya). Selain itu, terdapat faktor pendukung lain yang menyebabkan mutu pelayanan rendah di rumah sakit, yakni kuantitas dan kualitas perawat, jumlah dokter spesialis, dan alokasi pendanaan masih terfokus pada fisik dan peralatan. Alokasi dana yang kecil ini merupakan salah satu alasan terhambatnya 
peningkatan mutu pelayanan (Arifin dkk., 2011).

Six Sigma adalah sebuah metode ilmiah yang digunakan untuk memecahkan berbagai masalah di bidang industri dan bisnis. Six Sigma berorientasi pada proses serta mendegah terjadinya kegagalan dalam proses pelayanan tersebut. Six Sigma juga merupakan suatu program untuk meningkatkan kualitas, di mana terdapat proses pengukuran, investigasi, analisis, dan evaluasi dari suatu masalah. Analisis ini dilakukan dengan melihat sampai ke akar penyebab masalah, di mana masalah yang timbul menjadi sebab dari ketidakpuasan pasien yang merupakan pelanggan rumah sakit (Sunaringtyas, 2014).

Dari jurnal (Hidayatul Ulumiyah, Nurul. 2018. Meningkatkan Mutu Pelayanan Kesehatan Dengan Penerapan Upaya Keselamatan Pasien Di Puskesmas Jurnal : Jurnal Administrasi Kesehatan Indonesia Volume 6 No 2 July-December Published by Universitas Airlangga Doi: 10.20473/jaki.v6i2.2018.149155)

Keselamatan pasien menurut Permenkes RI No. 11 Tahun 2017 tentang
Keselamatan Pasien adalah sistem yang membuat asuhan pasien lebih aman, meliputi asesmen risiko, identifikasi dan pengelolaan risiko pasien, pelaporan dan analisis insiden, kemampuan belajar dari insiden dan tindak lanjutnya, serta implementasi solusi untuk meminimalkan timbulnya risiko dan mencegah terjadinya cedera yang disebabkan oleh kesalahan akibat melaksanakan suatu tindakan atau tidak mengambil tindakan yang seharusnya diambil. Upaya Keselamatan Pasien yang diterapkan oleh Puskesmas X Kota Surabaya bertujuan untuk meningkatkan mutu pelayanan fasilitas pelayanan kesehatan melalui penerapan manajemen risiko yang diterapkan ke seluruh aspek pelayanan yang disediakan oleh Puskesmas X Kota Surabaya. Selain itu, upaya keselamatan pasien juga menjamin bahwa seluruh tindakan dalam pelayanan kesehatan dilaksanakan sesuai dengan standar pelayanan minimal dan kode etik profesi tenaga kesehatan. Tingginya angka insiden keselamatan pasien menjadi dasar pentingnya upaya keselamatan pasien di fasilitas pelayanan kesehatan. Dalam rentang waktu JanuariDesember 2016, National Patient Safety Agency melaporkan angka kejadian 
keselamatan pasien dari negara Inggris sebanyak 1.879 .822 kejadian. Kementerian Kesehatan Malaysia (Ministry of Health Malaysia) melaporkan angka insiden keselamatan pasien dalam rentang waktu Januari-Desember 2013 sebanyak 2.769 kejadian dan untuk negara Indonesia dalam rentang waktu 2006 2011 KPPRS melaporkan terdapat 877 kejadian keselamatan pasien. Banyak faktor yang menyebabkan tingginya angka Insiden Keselamatan Pasien (IKP) di fasilitas pelayanan kesehatan. Selain faktor penyebab, dampak yang ditimbulkan dari Insiden Keselamatan Pasien juga beragam salah satunya adalah menurunnya kepuasan pasien sehingga berpengaruh terhadap mutu dari pelayanan kesehatan tersebut. Pelayanan yang aman dapat meningkatkan kepuasan pasien sehingga memberikan pengaruh yang baik terhadap citra dari sebuah fasilitas pelayanan kesehatan. METODE Artikel ilmiah ini merupakan jenis artikel ilmiah deskriptif. Teknik pengumpulan data yang dilakukan adalah dengan observasi langsung, wawancara dan studi literatur berdasarkan kebijakan dan dokumen yang terkait dengan mutu dan keselamatan pasien. Observasi langsung dilakukan untuk melihat proses pelaksanaan upaya keselamatan pasien di Puskesmas X Kota Surabaya. Wawancara dilakukan kepada tim Mutu dan Keselamatan Pasien dengan menggunakan panduan wawancara yang disesuaikan dengan Permenkes No. 46 Tahun 2015 dan Instrumen Akreditasi Puskesmas. Sedangkan dokumen yang digunakan sebagai literatur adalah pedoman, kebijakan dan/atau peraturan yang berlaku terkait mutu dan keselamatan pasien. Pengumpulan data dilaksanakan di Puskesmas X Kota Surabaya pada bulan Januari-Februari 2018.

\section{PEMBAHASAN}

Menurut Peraturan Kementrian Kesehatan (Permenkes) RI No. 159a/Menkes/PER/II/1998 tentang rumah sakit, akreditasi adalah suatu pengakuan yang diberikan oleh pemerintah pada manajemen rumah sakit, karena telah memenuhi standar minimal yang ditetapkan. Sedangkan menurut Permenkes RI No. 012/2012, menyatakan bahwa akreditasi rumah sakit adalah pengakuan terhadap rumah sakit yang diberikan oleh lembaga independen penyelenggara akreditasi yang ditetapkan oleh mentri baik dari dalam maupun luar 
negeri, baik pemerintah maupun swasta yanng bersifat mandiri dalam proses pelaksanaan, pengambilan keputusan, dan penerbutan sertifikat status akreditasi.

Adapun tujuan akreditasi rumah sakit adalah meningkatkan mutu pelayanan kesehatan, sehingga sangat dibutuhkan oleh masyarakat Indonesia yang semakin selektif dan berhak mendapatkan pelayanan yang bermutu. Dengan meningkatkan mutu pelayanan kesehatan diharapkan dapat mengurangi minat masyarakat untuk berobat keluar negeri.

Dari jurnal (Fajrianti, Kania Nabila,Ahmad Muhtadi.2010.

Peningkatan Mutu Pelayanan Kesehatan Di Rumah Sakit Dengan Six Sigma: Farmaka Volume 15 Nomor 3) Tingkat kenyamanan yang diberikan oleh penyedia jasa sangat memengaruhi baik kepuasan maupun ketidakpuasan seseorang terhadap proses pelayanan yang diterima olehnya. Maka dari itu, proses pelayanan kesehatan yang diberikan pihak rumah sakit hendaknya mampu menunjang kesembuhan fisik pasien. Selain itu, hendaknya juga dapat meningkatkan kepercayaan diri pasien untuk berusaha melawan penyakit yang diderita olehnya. Dengan demikian, jasa kesehatan harus terjangkau oleh masyarakat dan tersedia secara merata (Sunaringtyas, 2014).

Kualitas pelayanan dapat diartikan sebagai perbedaan antara pelayanan yang diterima secara nyata dengan harapan pelanggan. Di industri perawatan kesehatan, terdapat jenis-jenis pelayanan yang sama yang disediakan oleh rumah sakit, namun kualitas pelayanannya belum tentu sama. Pasien adalah pelanggan sehingga menjadi bagian yang sangat penting dalam perkembangan industri kesehatan (Setyaningsih, 2013).

Penyebab mutu pelayanan yang rendah di antaranya faktor input (peralatan, dana, kurangnya fasilitas, tenaga dokter ahli, dan sebagainya). Selain itu, terdapat faktor pendukung lain yang menyebabkan mutu pelayanan rendah di rumah sakit, yakni kuantitas dan kualitas perawat, jumlah dokter spesialis, dan alokasi pendanaan masih terfokus pada fisik dan peralatan. Alokasi dana yang kecil ini merupakan salah satu alasan terhambatnya 
peningkatan mutu pelayanan (Arifin dkk., 2011).

\section{KESIMPULAN}

Berdasarkan hasil penelusuran pustaka, diketahui bahwa kebijakan akreditas rumah sakit mampu meningkatkan mutu pelayanan kesehatan di rumah sakit.

\section{SARAN}

Untuk mendapatkan tingkat kelulusan akreditasi yang baik, diperlukan adanya kerja sama antar semua pihak di rumah sakit. Semua staf rumah sakit, mulai dari pimpinan puncak sampai staf lapis terbawah harus memiliki semangat yang sama dalam mewujudkannya. Pimpinan puncak hingga ke staf lapisan bawah harus memiliki pemahaman yang sama mengenai alasan dilaksanakannya akreditasi.

\section{REFERENSI}

Azwar, A 2010, Pengantar administrasi kesehatan, edk 3, Binarupa Aksara, Tangerang

Fajrianti, Kania Nabila,Ahmad Muhtadi.2010. Peningkatan Mutu
Pelayanan Kesehatan Di Rumah Sakit Dengan Six Sigma:

Farmaka Volume 15 Nomor 3. Hidayatul Ulumiyah, Nurul. 2018. Meningkatkan Mutu Pelayanan Kesehatan Dengan Penerapan Upaya Keselamatan Pasien Di Puskesmas Jurnal : Jurnal Administrasi Kesehatan

Indonesia Volume 6 No 2 July-

December Published by

Universitas Airlangga Doi:

10.20473/jaki.v6i2.2018.149155

KARS, 2012, Standar akreditasi rumah sakit 6. Dedi, Uus, Fitriyani 2013,

'Analisis Manajemen Mutu

Pelayanan Kesehatan pada

Rumah Sakit Islam Karaw.

Kementerian Kesehatan Republik

Indonesia (2009) Undang-

Undang Republik Indonesia

Nomor 36 Tahun 2009 tentang

Kesehatan. Indonesia

Kementerian Kesehatan Republik

Indonesia (2014) Peraturan

Menteri Kesehatan Republik

Indonesia Nomor 75 Tahun 2014

tentang Pusat Kesehatan

Masyarakat. Indonesia. 
Simamora, R. H. "Buku Ajar Keselamatan

Pasien Melalui Timbang Terima

Pasien Berbasis Komunikasi

Efektif: SBAR.” (2018).।

Shobirin (2016) 'Hubungan Penerapan

Manajemen Puskesmas dan

Komitmen Kerja Petugas dengan

Mutu Pelayanan Pengobatan di

Poli Umum Puskesmas

Kabupaten Bangkalan', Jurnal

Penelitian Administrasi Publik,

2(2), pp. 513-526. Available

Stephen P. Robbins, T. A. J. (2008)

Perilaku Organisasi. 12th edn.

Jakarta: Salemba Empat

Sumarni (2017) 'Analisis Implementasi

Patient Safety Terkait

Peningkatan Mutu Pelayanan

Kesehatan di Rumah Sakit',

Jurnal Ners dan Kebidanan

Indonesia,

Ulrich, B. and Kear, T. (2014) 'Patient

Safety and Patient Safety Culture:

Foundations of Excellent Health

Care Delivery.', Nephrology

Nursing Journal.

Undang-Undang Republik Indonesia

Nomor 29 Tahun 2004, Praktek

Kedokteran.
Undang-undang Republik Indonesia

Nomor 44 Tahun 2009, Rumah

Sakit

Peraturan Menteri Kesehatan Republik Indonesia Nomor 755 Tahun 2011, Penyelenggaraan Komite Medik di Rumah Sakit.

R.H.Simamora (2019). Buku ajar pelaksanaaan indentifikasi pasien. Uwais Inspirasi indonesi

R.H. Simamora. (2019). The infiuence of Training handover based SBAR Communication for Improving patients safety. Indian journal of public heath research \& Deveopment

R.H. Simamora (2019). Documentation of Patient Identifikasi Into the hectronic system to improve the quality of nursing serviceec International) journal of soenrifio $\&$ technology tesearch. 